\title{
DAÑOS OCASIONADOS A LOS NIÑOS, NIÑAS Y ADOLESCENTES EN LAS INSTITUCIONES EDUCATIVAS ¿QUIÉN SE RESPONSABILIZA?
}

\author{
WHO IS LIABLE FOR ANY DAMAGE CAUSED TO CHILDREN \\ AND ADOLESCENTS IN SCHOOLS?
}

Ocner Córdova López ${ }^{1}$

\section{Resumen}

En este artículo analizamos de manera sucinta la responsabilidad civil que debe asumir la institución educativa respecto de los daños sufridos por los niños y adolescentes (en su condición de alumnos) cuando éstos se encuentran dentro de la institución educativa o bajo su autoridad; advertimos que, a pesar de existir instrumentos internacionales y nacionales, como la Convención sobre los Derechos del Niño del cual el Perú es parte y la Constitución Política del Estado, que establecen un deber del Estado de brindar protección especial al niño y al adolescente, éstos vienen sufriendo daños dentro de las instituciones educativas o bajo su autoridad. En nuestro medio no se ha establecido una responsabilidad civil frente al incumplimiento de este deber de protección que genera daños a los menores en las instituciones educativas.

Palabras clave: Institución educativa, deber de protección, responsabilidad civil, daños sufridos por los niños y adolescentes.

\section{Abstract}

In this article, we briefly analyze the civil responsibility that the educational institution must assume regarding the damages suffered by children and adolescents (as students) when they are inside the educational institution or under its authority; we warn that, in spite of existing international and national instruments, such as the Convention on the Rights of the Child of which Peru is a party and the Political Constitution of the State, which establish a duty of the State to provide special protection to children and adolescents, they are suffering damages within educational institutions or under their authority. In our environment, no civil liability has been established against the breach of this duty of protection that causes harm to minors in educational institutions.

Magistrado de la Corte Superior de Justicia de Lima Este -Poder Judicial del Perú. Magíster en Derecho Civil; Juez titular del Segundo Juzgado Civil de San Juan de Lurigancho. 
Keywords: Educational institution, duty of protection, civil liability, damages suffered by children and adolescents.

\section{INTRODUCCIÓN}

Partimos del conocimiento de que tanto la Convención sobre los derechos del niño como la Constitución Política del Estado estatuyen un deber del Estado de proteger especialmente al niño y adolescente. Este deber de protección se debe realizar en cualquier ámbito en que se encuentre el niño o adolescente; así por ejemplo, cuando se encuentra dentro de las instituciones educativas o bajo su autoridad; sin embargo, existen estadísticas que demuestran una realidad distinta, que revelan que se viene incumpliendo, por las personas responsables de dirigir las instituciones educativas, con este deber de protección y cuidado que se le debe brindar al menor en su condición de alumno. Las más recientes estadísticas nos demuestran que los niños y adolescentes, cuando están dentro de una institución educativa o bajo su autoridad, en su condición de alumnos, vienen sufriendo daños de todo tipo, físico, psicológico, moral, sexual, etc. Se ha determinado que en los últimos cinco años se han registrado 19,157 casos de violencia contra los niños y adolescentes ocurridos en las instituciones educativas debidamente registrados, lo que nos permite concluir que el Estado, a través de las instituciones educativas públicas o privadas no está cumpliendo con su deber de protección. No obstante que existe una obligación de protección que corresponde asumir, en este caso a las instituciones educativas, a través de sus titulares; sin embargo, no existe una consecuencia cuando se incumple con esta obligación; no se ha legislado en forma específica quién responde por el daño que han sufrido el niño y el adolescente cuando se encuentran dentro de las instituciones educativas o bajo su autoridad.

En efecto, las instituciones educativas, a través de sus titulares ( $E l$ Estado cuando es una institución educativa pública y la persona natural o jurídica cuando es una institución educativa privada), no solo asumen una obligación de enseñar conforme a la malla curricular dictada por el Ministerio de Educación, sino que, junto a esta importante obligación también existe otra de igual importancia, esto es la obligación de protección y cuidado, que viene impuesta nada menos que por la Convención sobre los Derechos del Niño y la Constitución Política del Estado. Así como existe una responsabilidad por la omisión del primero de los deberes, también debe existir una responsabilidad civil por la omisión del deber de protección y cuidado. Por tanto, los titulares de las instituciones educativas resultan ser los responsables civilmente cuando se produce un daño al niño o adolescente (salvo caso fortuito o fuerza mayor) dentro de la institución 
educativa y bajo su autoridad, pues habrían incumplido con su obligación de protección y cuidado. Sin embargo, ante la ausencia en nuestro Código Civil de una norma jurídica que regule en forma específica respecto de la persona que asume la responsabilidad civil de resarcir los daños, se produce muchas que la víctima no sea reparada de modo integral o no sea resarcida como corresponde, máxime si se trata de un menor de edad.

Resulta importante que se dicte una disposición normativa en nuestro Código Civil que regule específicamente este tipo de responsabilidad, ello contribuiría a que las instituciones educativas, a través de sus titulares, tomen medidas de precaución para evitar el daño y con ello evitar resarcir, cumpliéndose así una de las modernas funciones de la responsabilidad civil, esto es la función preventiva; también ayudaría a las víctimas a saber con certeza ante quién dirigirán su pretensión resarcitoria por el daño sufrido; y ayudaría a los jueces a resolver de manera más pronta los casos sometidos a su jurisdicción. La institución educativa es un lugar en donde se encuentran múltiples actores bajo los cuales se encuentran sometidos los alumnos menores de edad, tales como el director, sub director, profesores, auxiliares y principalmente el titular de la institución educativa (el Estado o persona natural o jurídica), entre otros, cualquiera de ellos puede producir un daño, por omisión o por comisión, por un defecto en la infraestructura, o puede que el daño sea producido por otro menor o no se tenga conocimiento de quién produjo el daño.

Todo niño y adolescente tiene el derecho de recibir una educación libre de violencia y el Estado, a través de sus instituciones educativas públicas y privadas, tiene la obligación de brindárselas, esta obligación viene impuesta por la Convención sobre los Derechos del Niño y por la Constitución Política del Estado; en consecuencia, su omisión, que se produce cuando ocurre un daño al niño, debe generar responsabilidad civil consistente en la obligación de reparar ese daño de modo integral; en este sentido, a efectos de garantizar el derecho al resarcimiento por el daño sufrido, teniendo en consideración el interés superior del niño, se deben dictar las disposiciones normativas que lo aseguren o como bien lo precisa el artículo $3^{\circ}$ de la Convención, el Estado para cumplir con el rol protector "tomarán todas las medidas legislativas y administrativas adecuadas".

\section{II. ÁMBITO LEGAL DE PROTECCIÓN A LOS NIÑOS, NIÑAS Y ADOLESCENTES}

Nuestra Constitución Política del Estado establece en su artículo $4^{\circ}$ que "La comunidad y el Estado protegen especialmente al niño, al adolescente 
$(\ldots)^{\prime \prime}$. Por su parte, la Convención sobre los Derechos del Niño² en su artículo $3^{\circ}$ establece que los Estados Partes se comprometen a asegurar al niño la protección y el cuidado que sean necesarios para su bienestar, teniendo en cuenta los derechos y deberes de sus padres, tutores $u$ otras personas responsables de él ante la ley y, con ese fin, tomarán todas las medidas legislativas y administrativas adecuadas; asimismo, preceptúa que los Estados Partes se asegurarán de que las instituciones, servicios y establecimientos encargados del cuidado o la protección de los niños cumplan las normas establecidas por las autoridades competentes, especialmente en materia de seguridad, sanidad, número y competencia de su personal, así como en relación con la existencia de una supervisión adecuada. Por su parte, la Declaración de los Derechos del Niño, estableció como el segundo de sus principios, que: "El niño gozará de una protección especial y dispondrá de oportunidades y servicios, dispensado todo ello por la ley y por otros medios, para que pueda desarrollarse física, mental, moral, espiritual y socialmente en forma saludable y normal, así como en condiciones de libertad y dignidad. Al promulgar leyes con este fin, la consideración fundamental a la que se atendrá será el interés superior del niño". También nuestro Código de los Niños y Adolescentes en su artículo $4^{\circ}$ precisa que el niño y el adolescente tienen derecho a que se respete su integridad moral, psíquica y física y a su libre desarrollo y bienestar.

\section{NUESTRA REALIDAD PROBLEMÁTICA, VIOLENCIA CONTRA LOS NIÑOS, NIÑAS Y ADOLESCENTES EN LAS INSTITUCIONES EDUCATIVAS}

Si bien existen disposiciones normativas de ámbito internacional y nacional que imponen al Estado el deber de proteger y garantizar dicha protección al niño y adolescente, en su integridad moral, psíquica y física, así como en su libre desarrollo y bienestar en el lugar donde se encuentre, sin embargo, pareciera que dichas disposiciones normativas resultan insuficientes para evitar que los niños y adolescentes sufran daños en su persona (daños físicos, psíquicos, morales, etc.) precisamente en las escuelas o instituciones educativas, que es el lugar en donde se debe garantizar una protección integral y plena, pues la institución educativa debe ser un espacio seguro en donde el niño y adolescente va aprender y a formarse tanto intelectual como emocionalmente en las primeras etapas de su vida, es el lugar en donde transcurre parte de su vida.

En efecto, según el portal Si SeVe (Plataforma de denuncias sobre violencia escolar del MINEDU), en los últimos cinco años (2013 -2018) se reportaron 19,157 casos de violencia contra los niños y adolescentes en las instituciones

Aprobada por la Asamblea General de las Naciones Unidas, y ratificada por el Estado Peruano mediante Resolución Legislativa $\mathrm{N} \cdot{ }^{\circ} 25278$. 
educativas, la mayoría se registró en Lima, Piura y Junín. Se registró que 10,530 casos se refieren a violencia física, 8,860 casos se refieren a violencia verbal, 7,437 a violencia psicológica, mientras que 2,545 son por violencia sexual. Lo más preocupante, sin embargo, es que, en el $44 \%$ de los casos, los agresores fueron docentes o el personal del centro educativo. Se anota también que del cien por ciento de los casos de violencia registrados, se ha determinado que el $84 \%$ ocurre en colegios del Estado y el 16\% en colegios privados (www.siseve.pe).

Esta cifra de casos de violencia en contra de nuestros niños y adolescentes es preocupante, y solo estamos antes casos que han sido denunciados, porque es verdad que también existen casos de violencia escolar que no son denunciados por los menores víctimas de violencia, quizás por temor a represalias u otros motivos, lo que indudablemente aumentaría la cifra de violencia.

\section{IV. ¿QUIÉN SE RESPONSABILIZA POR LA REPARACIÓN INTEGRAL DEL DAÑO SUFRIDO POR EL MENOR?}

La violencia ejercida contra un niño o adolescente en la institución educativa genera daños ¿Quién responde civilmente por ese daño? ¿A quién corresponde su resarcimiento?

En una institución educativa -de nivel inicial, primario o secundarioexisten un amplio número de personas que la dirigen en diferentes niveles; así encontramos, por ejemplo, al titular o dueño del centro educativo en colegios privados (que puede ser una persona natural o una persona jurídica) y que en los colegios públicos sería el Estado; el director de la escuela, el subdirector, el profesor, el auxiliar, el asistente, el vigilante, etc., todos ellos ejercen de alguna manera autoridad sobre el menor.

¿Qué es lo que ocurre cuando el daño ha sido producido por alguien que pertenece a un conjunto más o menos amplio de personas, cuando no es posible determinar cuál de ellas es la verdadera causa del daño?

Cuando un menor de edad asiste a una institución educativa, de nivel primario o secundario, con la finalidad de que esta le brinde un servicio de enseñanza, puede ocurrir que, en el transcurso de su formación educativa, cuando se encuentra dentro de la institución educativa o bajo el control de la autoridad educativa, el menor sufra un daño (daño moral, físico, sexual, psicológico, etc.), cuyo origen del daño puede ser diverso, esto es puede resultar como consecuencia de la agresión física u hostigamiento constante (bullying por ejemplo) de otro estudiante o un grupo de estudiantes hacia el menor, el daño también lo puede hacer un personal de la institución 
educativa o provenir de una deficiente estructura del centro educativo, daño producido por un tercero que ingresa a la institución educativa, o el daño resulta como consecuencia de un caso fortuito o fuerza mayor, etc., o incluso no se tenga conocimiento de quién produjo el daño al menor. El acto dañoso del menor puede también producirse a causa de un defecto en las medidas de organización adoptadas por el centro educativo.

Nadie espera que su hijo menor de edad que llega sano a la institución educativa sufra dentro de ella un daño (físico, psíquico, moral o sexual); sin embargo, es una realidad que existe y que suele ocurrir conforme a las estadísticas reportadas por el MINEDU (www.siseve.pe). Por tanto, una vez comprobada la existencia del daño en el menor, existe un deber de reparar ese daño, deber de reparar que se vuelve más exigente cuando se trata de los intereses de un menor de edad. Entonces, ante la existencia del daño y el deber de repararlo, corresponde preguntarse ¿Quién debe responder civilmente por el daño ocasionado o sufrido por el menor cuando este se encuentra dentro de las instalaciones de la institución educativa o bajo la autoridad de la referida institución?

Actualmente, en nuestro Código Civil no existe una norma jurídica que regule específicamente este tipo de responsabilidad civil, una norma civil que determine a quién corresponde resarcir el daño producido a un menor cuando éste se encuentre dentro de las instalaciones educativas o bajo el control de la autoridad educativa. Fácilmente podría argumentarse que responde quien produjo el daño; sin embargo, estando a la especial vulnerabilidad del niño, puede suceder que no se pueda determinar quién realmente produjo el daño (pero el niño resultó dañado) ¿quién se responsabiliza? o que el daño lo ocasionó otro niño ¿podría responsabilizarse civilmente en este caso al niño agresor? ¿Tiene capacidad para asumir una responsabilidad de esa naturaleza? $\mathrm{O} i \mathrm{~A}$ sus padres del niño agresor que no estuvieron presentes para vigilar al menor? ¿No tendría acaso ninguna responsabilidad la institución educativa a través de su titular? ¿Acaso no correspondía a la institución educativa la obligación de brindar protección y cuidado al menor, lo que significaría que no se produzca ningún tipo de daño? ¿No habrá una consecuencia de resarcir el daño por quien no cumplió con su obligación de protección?

\section{LA OBLIGACIÓN DE LA INSTITUCIÓN EDUCATIVA NO SOLO ES DE ENSEÑAR}

¿Acaso la obligación de la institución educativa es solo de enseñar a leer y a escribir y dictar los cursos conforme a la malla curricular? Si respondemos afirmativamente esta pregunta estaríamos desconociendo lo 
que textualmente nos dice la Convención sobre los Derechos del Niño que en su artículo $3^{\circ}$ señala: "Los Estados parte se comprometen a asegurar al niño la protección y cuidado ..." y la Constitución Política del Estado, que en su artículo $4^{\circ}$ establece: "la Comunidad y el Estado protegen especialmente al niño, al adolescente..."; y en este mismo sentido, La Declaración de los Derechos del Niño establece como uno de sus principios: "El derecho a tener una protección especial para el desarrollo físico, mental y social del niño".

Si bien uno de los deberes que asume la institución educativa, ante los niños matriculados en su institución, es enseñar conforme a la malla curricular que establece el Ministerio de Educación; sin embargo, junto a este importante deber, existe otro de la misma importancia y categoría, cual es el deber de protección del niño mientras esté bajo su autoridad. Este deber de protección y cuidado viene impuesto por normas supremas, como son la Convención de los derechos del niño y la Constitución Política del Estado. Esta obligación de protección se traduce en una obligación de vigilancia y supervisión constante hacia el menor. En este sentido, la doctrina italiana ha señalado que: "la supervisión de los niños es una de las llamadas 'obligaciones implícitas', las que no están expresamente previstas en una norma, pero existen” (Tovani, 2012, p. 56).

El Tribunal Constitucional peruano ha señalado que existe un deber especial de protección de los derechos del niño y adolescente y es un deber del Estado y de toda la comunidad velar por su vigencia, así nos indica que:

El deber de protección sobre los derechos del niño vincula no solo a las entidades estatales y públicas sino también a las entidades privadas e inclusive a la comunidad toda, a fin de que cualquier medida que adopten o acto que los comprometa velen por el interés superior del niño, el cual debe anteponerse a cualquier otro interés. Por tanto, constituye un deber velar por la vigencia de los derechos del niño y de sus intereses. (...) Y es que la niñez constituye un grupo de personas de interés y de protección prioritaria del Estado y de toda la comunidad(...) [cursivas añadidas]. (Expediente 2079-2009-PHC/TC).

Así, también ha señalado el máximo intérprete constitucional, que: “El fundamento constitucional de la protección del niño y del adolescente que la Constitución otorga radica en la especial situación en que dichos menores de edad se encuentran, es decir, en plena etapa de formación integral, en tanto personas" (Exp. 3330-2004-AA/TC).

Respecto del deber de protección que deben asumir las instituciónes educativas, la doctrina española ha señalado que: "Es a los centros docentes 
durante las horas lectivas a quienes corresponde vigilar a los menores para evitar cualquier acto lesivo para la víctima y adoptar las medidas protectoras necesarias" (Mondéjar, 2011, p. 553). También se señala que: "Para acreditar su existencia hay que evidenciar que hubo una falta de atención, vigilancia, cuidado y respuesta inmediata y contundente por parte del centro escolar. El colegio tiene una función de garante de seguridad y bienestar físico y psíquico de sus alumnos que los obliga a actuar de manera efectiva" (Goenaga, 2015). Asimismo, en Argentina existe una corriente doctrinal uniforme que determina que la institución educativa asume un deber de seguridad frente al niño y adolescente, así se indica: “... los establecimientos educativos asumen contractualmente junto con la obligación principal de prestar educación, una obligación de seguridad cuyo incumplimiento hace nacer una responsabilidad directa y que la asunción de la misma significa garantizar la indemnidad del alumno en su integridad física y moral" (Kemelmajer, 1998, p. 1047).

Por su parte la doctrina colombiana también ha advertido la existencia de una obligación de cuidado a cargo de las instituciones educativas frente a los estudiantes menores de edad, de esta manera ha dicho: "Es así como la obligación de ser garantes de cuidado, propia de las instituciones educativas se concreta en una categoría conocida en la jurisprudencia colombiana como deber de cuidado que no es otra que la obligación que tiene la institución educativa de proteger la integridad física, emocional y moral de los estudiantes..." (Martínez, 2012, s/p).

En consecuencia, conforme a la doctrina más reciente, las instituciones de educación primaria y secundaria, públicas y privadas, tienen la obligación fundamental de garantizar a los niños, niñas y adolescentes el pleno respeto a su dignidad, vida, integridad física y moral dentro de la convivencia escolar; obligación que se hace efectiva a través de un adecuado deber de cuidado y vigilancia.

\section{RESPONSABILIDAD CIVIL DE LA INSTITUCIÓN EDUCATIVA FRENTE AL DAÑO SUFRIDO POR UN NIÑO Y ADOLESCENTE}

Si bien existe un deber de protección, que se traduce o concreta en un deber de vigilancia, supervisión, de cuidado, de seguridad, que deben asumir nuestras instituciones educativas cuando tengan bajo su autoridad a los niños y adolescentes; sin embargo, las estadísticas nos demuestran que este deber de protección no se está cumpliendo. Es lamentable que en los últimos cinco años 2013 al 2018 se hayan denunciado 19,157 casos de violencia contra los niños y adolescentes en las instituciones educativas públicas y privadas; y solo estamos ante casos denunciados, porque existirán muchos casos de violencia contra los 
niños que no fueron denunciados y por ende no registrados estadísticamente. En efecto, existen muchos casos que no se denuncian ante las autoridades por temor a represalias a sus agresores, por desconocimiento ante quien denunciar o cuando se denuncia ante el mismo director del colegio o profesor, este los ignora o aveces el padre opta por cambiar de colegio a su niño.

Ya hemos establecido que las instituciones educativas (primaria y secundaria) tanto estatales como privadas, tienen un ineludible deber de protección; este deber de protección impuesto por las normas supremas (Constitución y Convención), se traduce en un deber de vigilancia y de establecimiento de medidas internas que eviten cualquier tipo de daño a la integridad del menor. Así la doctrina italiana señala que: "El deber de educación está en correlación con el deber de vigilancia" (Alpa, 2006. p.849). El incumplimiento de este deber de vigilancia debe generar responsabilidad en las instituciones educativas; la institución educativa debería ser responsable civilmente de los daños causados a sus alumnos menores de edad durante los periodos de tiempo en que los mismos se hallen bajo su cuidado y atención, por tanto debería resarcir a la víctima.

Como ya se ha dicho y es bueno reiterarlo, en la institución educativa de menores existe un conjunto más o menos amplio de personas que están a cargo de la conducción de la institución en diferentes cargos. Así, tenemos por ejemplo, en un centro educativo privado al titular del centro educativo (persona natural o jurídica), director, subdirector, profesores, auxiliares, tutores, vigilantes, etc.; igualmente en un colegio estatal, el titular del centro educativo es el Estado y dentro de la institución encontramos al director, sub director, profesores, auxiliares, tutores, vigilantes etc. Ahora ¿quién de estas personas responde civilmente frente al daño ocasionado a un menor de edad? Si se lograra identificar que el daño lo produjo un profesor o auxiliar del centro, se atribuiría una responsabilidad civil individual conforme a lo previsto en el artículo $1969^{\circ}$ del Código Civil, el cual establece que: "Aquel que por dolo o culpa causa un daño a otro está obligado a indemnizarlo". Sin embargo, también puede suceder que no se pueda determinar quién ocasionó el daño al menor ¿se quedará el menor sin reparación de ese daño? $\mathrm{O}$ también que, quien produjo el daño se fugó o desapareció ¿quedaría sin reparación integral este niño? Cabe precisar, que al margen de la responsabilidad penal que pudiera haber, en caso que el acto sea considerado un delito, tendría que haber también una responsabilidad civil que dé origen a un resarcimiento económico a favor del menor víctima del daño.

Habrá ocasiones en que el daño que ha sufrido un niño o adolescente fue ocasionado por otro u otros niño ¿Cabe aquí atribuir responsabilidad civil al niño que ocasionó el daño? 
También pensemos que en el caso que el daño lo haya producido el profesor $\mathrm{u}$ otro dependiente de la institución educativa, ¿no tendría ninguna responsabilidad civil el titular de la institución educativa? Nos referimos como titular de la institución educativa al dueño del colegio privado o al Estado en caso de instituciones educativas estatales. ¿No es acaso el titular de la institución educativa quien para cumplir con su obligación de enseñanza y de protección se vale de los profesores y más dependientes? ¿No es acaso el titular de la institución educativa quien selecciona o tiene la responsabilidad de seleccionar a sus profesores y demás dependientes?

$\mathrm{Si}$ bien en las instituciones educativas existen directores y subdirectores que la dirigen, sin embargo, dicha dirección la hacen bajo las políticas y lineamientos establecidos por el titular de la institución educativa. En este sentido, se ha señalado que "aunque los directores de los colegios y otros próximos (como el jefe de estudios) pueden adoptar medidas de organización, lo hacen sobre la base de las líneas directrices marcadas por el titular del centro de enseñanza que es quien tiene el poder de organización de las actividades que en el mismo se realizan" (Atienza, 1999, p. xxx). También es bueno tener en consideración, por el principio del interés superior del niño que, quien está en mejores condiciones económicas para reparar integralmente el daño sufrido es el titular de la institución educativa, quien podría repetir contra el docente o auxiliar si estos fueran los responsables directos; lo importante es asegurar la reparación integral del daño al menor.

En consecuencia, en mi opinión, en todos los casos en que se produzca un daño al niño y adolescente dentro de la institución educativa o bajo su autoridad, debe responder civilmente el titular de la institución educativa, sea pública (El Estado) o privada aun cuando el daño lo haya producido el profesor $u$ otro dependiente $u$ otro niño y con mayor razón cuando no se tenga conocimiento de cómo se produjo el daño o cuando el daño se produjo por un defecto de la infraestructura; a menos que, se trate de un caso fortuito; responsabilidad que tiene su fundamento en el ineludible deber de protección y seguridad que deben brindar las instituciones educativas a los menores.

\section{DAÑO OCASIONADO AL MENOR POR OTRO NIÑO O ADOLES- CENTE}

No se puede atribuir responsabilidad civil u obligación de resarcir a un niño o al padre de éste por el daño que cause a otro niño estando dentro de la institución educativa o bajo su autoridad, por las siguientes razones: 
En principio, porque estamos ante menores de dieciséis años y de acuerdo con el artículo $43^{\circ}$ de nuestro Código Civil, los menores de dieciséis años son considerados "absolutamente incapaces"; en este sentido, se ha señalado que: "A la incapacidad absoluta se suele denominar 'incapacidad natural de obrar' por derivarse de una situación de hecho, de la naturaleza, en que se encuentra la persona, debido: 1) a que todavía no ha alcanzado un suficiente desarrollo mental como ocurre generalmente con los menores de 16 años" (Torres, 2016, p. 260).

Respecto a la responsabilidad de los incapaces el profesor Leysser León ha señalado que: "No sería admisible, desde ningún punto de vista, atribuir una "culpa" a los sujetos incapaces de discernimiento (...) para que se pueda verificar una antijuricidad semejante sería necesaria la posibilidad de referir al incapaz la violación de la ley, y ello no cabe, porque la norma jurídica está dirigida solo a los sujetos que están en condición de comprender y observar su contenido" (León, 2017, p. 615 y 616).

Los padres del niño que ha causado un daño tampoco podrían ser responsables civilmente, pues, si bien el artículo $1976^{\circ}$ del Código Civil establece que cuando el daño lo causa el incapaz de discernimiento responde su representante legal; sin embargo, debe entenderse esta norma jurídica que el representante legal del menor (los padres), responden siempre y cuando el daño se haya producido cuando el menor esté bajo su vigilancia y autoridad, $y$ no cuando el menor está bajo la vigilancia y autoridad de otra persona como es la institución educativa ¿Cómo podría el padre vigilar y establecer autoridad sobre el menor cuando ése se encuentra lejos de su esfera de control? ¿Cómo podría ser responsable el padre del menor agresor cuando dicho menor está bajo la vigilancia y autoridad de una institución? Así se ha señalado que: "no se puede exigir a los padres, por los daños que sus hijos ocasionen durante esos periodos de tiempo en los que no puede hacer efectivas sus obligaciones de guarda" (Mondéjar, 2011, p. 550). Con más precisión se ha indicado que: "Los padres son responsables de los daños causados por sus hijos menores, la misma cesa cuando los coloca en un establecimiento educativo, trasladándose la responsabilidad a quien desde entonces los tiene bajo su custodia, guarda y vigilancia" (Albornoz, 2017). Asimismo, se ha señalado que: "si un niño está en el colegio sus padres no pueden hacer nada para impedir que observe una conducta inadecuada que produzca un daño. (...) la ley no acepta que los padres respondan sin más y por el hecho de serlo" (Ramón, 2012, p.21).

El fundamento de la responsabilidad de los padres por los hechos, daños de sus menores hijos no está en el hecho ser padres o en el mero vínculo parental, sino en el descuido del deber de vigilancia y de autoridad que todo 
padre debe tener hacia sus hijos menores. La responsabilidad de los padres es por hecho propio y no por el solo hecho de ser padres. La doctrina italiana ha establecido que la responsabilidad de los padres por los hechos de sus hijos radica en el deber de vigilancia y educación, y no en el mero vínculo parental, así se indica: "la responsabilidad del artículo 2048 del Código Civil es una responsabilidad culposo por un hecho propio de los padres. Tal orientación encuentra su fundamento en la convicción de que los padres responden en virtud de dicho precepto, no en función del mero vínculo parental que los une con el menor autor del hecho, sino por el contrario en razón de las obligaciones de vigilancia y educación que incumbe a quienes ejercitan la potestad sobre él; solo la obligación por parte de los progenitores de estas obligaciones puede determinar el nacimiento de responsabilidad" (Berti, 2014, p. 316).

En consecuencia, si el fundamento de la responsabilidad de los padres por el hecho de sus hijos menores radica en el deber de vigilancia y educación, los padres no tendrán responsabilidad ante el hecho producido por su hijo cuando éste no está en la esfera de su vigilancia y cuidado; si el hecho se produjo cuando el niño se encontraba bajo la vigilancia y autoridad de la institución educativa, es evidente que es ésta quien asume la responsabilidad total por el daño y no el padre.

\section{REGULACIÓN EN EL DERECHO COMPARADO DE LA RESPONSA- BILIDAD CIVIL POR LOS DAÑOS OCASIONADOS O SUFRIDOS POR LOS MENORES EN LAS INSTITUCIONES EDUCATIVAS}

En nuestro Código Civil no existe una norma jurídica que regule específicamente el daño sufrido por un menor en la institución educativa o cuando se encuentre bajo su autoridad. ¿Es necesario hacerlo? El problema de la falta de una regulación especial sobre el tema afecta directamente a la víctima menor de edad, pues éste no tiene la certeza de definir contra quien va a dirigir su pretensión de resarcimiento ante el daño sufrido; si como ya se ha dejado establecido, las instituciones educativas se encuentran obligadas a brindar protección y cuidado a los menores, la violación de esta obligación que se produce cuando ocurre el daño, debe generar una responsabilidad civil en dicha institución educativa (en su titular), al margen de qué persona específicamente produjo el daño al niño. Si uno de los objetivos de la responsabilidad civil es la reparación integral del daño sufrido, se lograría mejor este objetivo si normativamente establecemos la obligación de reparar el daño al titular de la institución educativa (persona natural o jurídica en las instituciones educativas privadas y el Estado en las instituciones educativas públicas). El titular cuenta con los medios económicos suficientes para reparar el daño; el titular en todo 
caso, podría repetir contra el profesor causante del daño cuando éste haya causado el daño como sucede por ejemplo en otras legislaciones; también podría establecerse que la víctima del daño pueda dirigir su pretensión de resarcimiento indistintamente contra el titular de la institución educativa y/o contra el profesor, aunque este último sí respondería bajo la regla establecida en el artículo $1969^{\circ}$ del Código Civil en los casos en que se determine que éste de manera dolosa o culposa causó el daño al niño.

Debemos tener en cuenta que por encima de cualquier interés que puedan tener los titulares de las instituciones educativas o que se les pueda afectar, está el interés superior del niño que implica que en todas las decisiones que se tomen y conciernan a los niños, se tomará en cuenta siempre de manera prioritaria su bienestar.

Lo importante es que el niño víctima del daño ocurrido dentro de la institución educativa no quede sin reparación, que su reparación sea íntegra y no a medias; que las instituciones educativas sepan que el no brindar una protección y seguridad a los niños que tiene matriculados constituye un responsabilidad civil.

Si bien en nuestra legislación civil no se encuentra regulada la responsabilidad civil que se pueda originar ante los daños ocasionados o sufridos por los menores de edad cuando estos se encuentran dentro de las instituciones educativas o bajo la autoridad, sin embargo, sí existen en el derecho comparado legislaciones civiles de otros países latinoamericanos y europeos que sí regulan específicamente este tipo de responsabilidad, como a continuación veremos:

Argentina: El "Nuevo Código Civil y Comercial de la Nación" en su artículo $1767^{\circ}$ se establece lo siguiente: “El titular de un establecimiento educativo responde por el daño causado o sufrido por sus alumnos menores de edad cuando se hallen o deban hallarse bajo el control de la autoridad escolar. La responsabilidad es objetiva y se exime solo con la prueba del caso fortuito. El establecimiento educativo debe contratar un seguro de responsabilidad civil, de acuerdo a los requisitos que fije la autoridad en materia aseguradora. Esta norma no se aplica a los establecimientos de educación superior o universitaria".

Colombia: El Código Civil de Colombia en su artículo $2347^{\circ}$ indica lo siguiente: "Así, los directores de colegios y escuelas responden del hecho de los discípulos mientras están bajo su cuidado, y los artesanos y empresarios del hecho de sus aprendices, o dependientes, en el 
mismo caso. Pero cesará la responsabilidad de tales personas, si con la autoridad y el cuidado que su respectiva calidad les confiere y prescribe, no hubieren podido impedir el hecho".

Chile: El Código Civil chileno en su artículo $2320^{\circ}$ estipula que: “Toda persona es responsable no sólo de sus propias acciones, sino del hecho de aquellos que estuvieren a su cuidado. (....). Así los jefes de colegios y escuelas responden del hecho de los discípulos, mientras están bajo su cuidado; (...). Pero cesará la obligación de esas personas si con la autoridad y el cuidado que su respectiva calidad les confiere y prescribe, no hubieren podido impedir el hecho".

Paraguay: El Código Civil paraguayo en su artículo $1843^{\circ}$ establece lo siguiente: “(...). Los directores de colegios y los artesanos son responsables de los daños causados por sus alumnos o aprendices, menores de edad, mientras permanezcan bajo su custodia. La responsabilidad de que trata este artículo cesará si las personas mencionadas en él prueban que no pudieron prevenir el daño con la autoridad que su calidad les confería, y el cuidado que era de su deber emplear. (...)".

Costa Rica: El Código Civil de la república de Costa Rica, establece en su artículo $1048^{\circ}$ lo siguiente: “Los jefes de colegios o escuelas son responsables de los daños causados por sus discípulos menores de quince años, mientras estén bajo su cuidado. (...). Cesará la responsabilidad de las personas dichas, si prueban que no habrían podido impedir el hecho de que se origina su responsabilidad, ni aún con el cuidado y vigilancia común u ordinaria."

España: El artículo $1903^{\circ}$ del Código Civil español establece que: "Las personas o entidades que sean titulares de un centro docente de enseñanza no superior responderán por los daños y perjuicios que causen sus alumnos menores de edad durante los períodos de tiempo en que los mismos se hallen bajo el control o vigilancia del profesorado del centro, desarrollando actividades escolares o extraescolares y complementarias. (...)".

Italia: El artículo $2048^{\circ}$ del Código Civil italiano, estipula lo siguiente: “(...). Los preceptores $\mathbf{y}$ aquellos que enseñan un oficio o un arte son responsables del daño ocasionado por el hecho ilícito de sus alumnos y aprendices en el tiempo en que han estado bajo su vigilancia. Las personas indicadas por los apartados anteriores quedan liberadas de la responsabilidad solamente si prueban no haber podido impedir el daño". 
Francia: El artículo $1384^{\circ}$ del Código Civil francés preceptúa que: “(...) Los maestros y los artesanos, del daño causado por sus alumnos y aprendices mientras estuviesen bajo su supervisión. (...). En lo que concierne a los maestros, las faltas, imprudencias o negligencias invocadas contra ellos como causantes del hecho dañoso deberán ser probadas, con arreglo al derecho común, por el demandante en la instancia".

Del repaso de los códigos civiles tanto europeos como latinoamericanos, encontramos dos tendencias en cuanto a atribuir responsabilidad civil por el daño sufrido por los alumnos en las instituciones educativas. Por ejemplo, en los códigos civiles de Argentina y España establece la responsabilidad en el titular de la institución educativa. Así, el primero dice: "El titular de un establecimiento educativo responde por el daño causado o sufrido por sus alumnos menores de edad..." y el segundo señala: "Las personas o entidades que sean titulares de un centro docente de enseñanza no superior responderán por los daños y perjuicios que causen sus alumnos...". Por su parte, Colombia y Paraguay en sus respectivos códigos civiles se establecen específicamente que son responsables los "directores de colegio" mientras que en Chile y Costa Rica atribuye responsabilidad a los "Jefes de Colegio", debiendo entenderse a éstos como los directores de los centros educativos.

En nuestro Código Civil no existe una disposición normativa que regule específicamente la responsabilidad civil por los daños sufridos $\mathrm{u}$ ocasionados a los menores cuando éstos se encuentran dentro de la institución educativa o bajo su autoridad. Debiera existirlo, ello, como ya se dijo, facilitaría a las víctimas -niños y adolescentes- a recibir una reparación integral por daños sufridos; asimismo, ayudaría a los jueces a resolver con prontitud y certeza cuando llegue a sus despachos una demanda de esta naturaleza sin entrar en la discusión y probanza de quién es la responsabilidad. Una disposición normativa de esta naturaleza también contribuiría a que los titulares de los centros educativos sean más cuidadosos y conscientes en cuanto al deber de protección y vigilancia hacia el menor, debiendo dictar políticas y medidas de organización a efectos de evitar y prevenir cualquier tipo de daño contra el niño y el adolescentes; y es que, precisamente, una de las nuevas funciones que destaca la doctrina moderna de la responsabilidad y que ha cobrado protagonismos es la función preventiva (León, 2017, p. 28); a través de esta función se busca que el ente responsable ante un posible daño tome las medidas preventivas y de seguridad para evitar el daño, puesto que de ocurrir el daño responderían civilmente. 


\section{EL ESTADO ASUME UNA POSICIÓN DE GARANTE}

El Estado está en la obligación de garantizar a los niños y adolescentes a recibir una educación libre de violencia, "esta posición de garante viene impuesta al Estado también, por la Convención sobre los derechos del Niño, la cual, al ser ratificada por la asamblea legislativa, tiene fuerza superior a ley. De conformidad con dicha Convención, los Estados partes se comprometen, de manera indeclinable, a respetar los derechos de los niños en ella enunciados" (Bolaños, 2002, p, 135). La Convención sobre los Derechos del Niño impone a los estados partes el compromiso de asegurar al niño la protección y el cuidado necesarios para su bienestar así como la obligación de asegurarse de que las instituciones, servicios y establecimientos encargados de cuidado o la protección de los niños cumplan las normas establecidas en materia de seguridad, sanidad, personal y existencia de una supervención adecuada.

Es obligación de Estado convertirse en un garante de la seguridad y protección de nuestros niños y adolescentes, para ello tiene el deber de dictar las disposiciones normativas dirigidas a erradicar y prevenir este tipo de daños en nuestros menores y cuando esto ocurra que sean debidamente resarcidos. Así, se ha dicho que "un Estado pasivo frente a estos fenómenos de violación de derechos puede constituirse -internacionalmente- en responsable. Y no solamente responsable de lo que hace o no hace directamente, sino de lo que terceros, particulares, agresores, que lesionan a los niños y por cuyas conductas el Estado también debe responder, evitándolas o previniéndolas" (García, 2015, p.143). También se ha puntualizado que: “Un Estado puede incurrir en responsabilidad internacional, por violación de sus obligaciones de garantía ¿garantía de qué? De los derechos y de las libertades ¿a quiénes? De todos los que se hayan bajo su jurisdicción; pero muy especialmente de aquellos que no pueden garantizar por sí mismos esos derechos y libertades. Los niños son débiles, por antonomasia, los que no pueden por si mismos garantizar la observancia de sus derechos" (García, 2015, p.144).

En mi consideración lo dispuesto por los Códigos Civiles de Argentina y España son las mejores disposiciones que regulan la responsabilidad por los daños ocurridos a los menores en las instituciones educativas, pues ellas atribuyen responsabilidad a los titulares de los centros educativos, son los titulares quienes escogen su personal, son ellos quienes deben dictar las medidas de seguridad, y en el caso de una institución educativa privada, son los titulares quienes se benefician económicamente y en el caso de instituciones educativas de carácter público es el Estado quien asume una posición de garante de una educación sin violencia. 


\section{CONCLUSIONES}

1. Existe un deber de protección y cuidado impuesto por la Convención sobre los derechos del niño y la Constitución Política del Estado, a favor de los niños y adolescentes, es por ello que las instituciones educativas, a través de sus titulares, asumen una responsabilidad civil cuando omiten este deber de protección.

2. Generado el daño al niño y adolescente cuando están dentro de las instituciones educativas o bajo su autoridad, debe existir una correspondiente obligación de reparar de modo integral ese daño sufrido, responsabilidad que debe asumir necesariamente el titular de la institución educativa.

3. La ausencia en nuestro Código Civil de una disposición normativa que regule específicamente la responsabilidad de las instituciones educativas por los daños sufridos por los menores cuando se encuentran bajo sus instalaciones o bajo su autoridad, genera que muchas veces el daño sufrido por el menor no sea resarcido o reparado integralmente, y que las instituciones educativas no tomen las medidas necesarias para prevenir el daño.

4. El fundamento constitucional de la protección del niño y del adolescente que la Constitución otorga radica en la especial situación en que dichos menores de edad se encuentran, en plena etapa de formación integral.

5. El Estado es garante de la integridad (moral, física, psíquica) y de la educación de nuestros niños y adolescentes; por tanto, puede incurrir en responsabilidad por acción o por omisión.

\section{REFERENCIAS}

Albornoz, Marcelo E. (2017). La violencia escolar y los maltratos. Recuperado de https: / / mayeuticaeducativa.idoneos.com/353802.

Alpa, Guido (2006). Nuevo tratado de la responsabilidad civil. Jurista Editores E.I.R.L.

Atienza Navarro, María Luisa (1999). Responsabilidad por hechos dañosos de los alumnos. Proceso de configuración de los criterios vigentes. Anales de Derecho. Universidad de Murcia. Número 17. 
Berti de Martins, Giovanni (2014). Educación de la prole y responsabilidad civil por los daños ocasionados por el hijo menor en el derecho italiano. Revista boliviana de Derecho, N 17, pp. 316-332. Fundación iuris tantun. Santa Cruz Bolivia.

Bolaños Gonzales, Jimmy (2002). La responsabilidad de los directores de centros educativos por daños ocasionados por sus alumnos. Revista Educación, volumen 26, número 1-2002, pp. 135-146. Universidad de Costa Rica

García Ramírez, Sergio Junio (2015). Bullying, desde la perspectiva de los Derechos Humanos. Cátedra Magistral. Revista de derecho privado. Cuarta Época, año IV, número 7.

Goenaga Llorca, Arantxa (2015). La responsabilidad civil de los centros escolares en los casos de bullying o acoso escolar. Recuperado de: http:/ /www. asociacionabogadosrcs.org/jurisprudencia/segurosmayo2015.pdf.

Kemelmajer de Carlucci, Aída (1998). La responsabilidad civil de los establecimientos educativos en la Argentina después de la reforma de 1997 La Ley, 1998-B-1047. 1998-B, 1047.

León Hilario, Leysser (2017). La responsabilidad civil. Líneas fundamentales. Tercera Edición. Editorial Pacífico.

Martínez, Rojas, José Guillermo (2012). El deber de cuidado y la responsabilidad civil de las instituciones educativas. Recuperado de: https// todosobrelaley.wordspress.com/2012/05/18/propuestas.

Mondéjar Peña, María Isabel (2011). La responsabilidad civil de los centros docentes por los daños causados por los alumnos menores de edad. Derecho de daños. Una perspectiva contemporánea. Motivensa Editores.

Ramón Fernández, Francisca (2012). Responsabilidad civil en el ámbito de los menores. Revista sobre la infancia y adolescencia $N^{\circ} 3$. Universidad Politécnica de Valencia. Recuperado de: https://polipapers.upv.es/index. $\mathrm{php} / \mathrm{reinad} /$ article/view/1118/1330.

Torres Vásquez, Aníbal. (2016). Código Civil comentado. Octava edición. Editorial IDEMSA.

Tovani, Flavio (2012). La responsabilidad de los padres en Italia. Aletheia. Cuadernos críticos del derecho. Liberlex. Recuperado de: http://www. liberlex.com/archivos/rpater_it.pdf.

Fecha de recepción : : 28 de agosto de 2018

Fecha de aceptación : : 25 de octubre 2018 